\title{
VIRTUAL REALITY USE FOR EVALUATION AND IMPROVEMENT OF BUILDING EMERGENCY SIGNAGE
}

\author{
Simon Swanström Wyke ${ }^{1}$, Kasper Meyer Andersen ${ }^{1}$, Mads Hardahl², Magnus Mejlholm Harlyk ${ }^{3}$, \\ Erik Vils Risbøl ${ }^{4}$ and Kjeld Svidt ${ }^{1}$ \\ ${ }^{1}$ Department of Civil Engineering, Aalborg University, Denmark \\ ${ }^{2}$ ERIK Arkitekter, Aalborg, Denmark \\ ${ }^{3}$ NIRAS, Aalborg, Denmark \\ ${ }^{4}$ Exigo A/S, Aarhus, Denmark
}

\begin{abstract}
Immersive Virtual Reality (VR) is often used to visualise architecture, interior design and building use. This study looks into the use of VR in evaluation of emergency signage with respect to fire evacuation. In a single case study experiment using Serious Gaming (SG), test persons were immersed into VR using a head mounted display (HMD) and asked to evacuate a test building in a fire evacuation scenario. The case study experiment provided a keen understanding into people's reaction to emergency signage and how detection of such signage during evacuation can be improved.
\end{abstract}

\section{Introduction}

In fire evacuation, certain design requirements must be fulfilled, securing the ability to evacuate a building rapidly, easily and safely, before being impacted by the fire (Trafik- og Byggestyrelsen, 2016) (Kobes et al., 2010). The evacuation time for building users can vary a lot, depending on pre-movement time and the actual movement speed during evacuation. How familiar a person is with a building is another factor to consider regarding evacuation time (Purser and Bensilum, 2001). Evacuation speed/ time is important, as research shows a correlation between delayed evacuation and number of fire deaths (Wang et al., 2014) (Purser and Bensilum, 2001). In this study evacuation time is understood as the time from evacuation is announced to a person is evacuated.

During evacuation, people are likely to prefer leaving a building through the same route as they entered (Trafik- og Byggestyrelsen, 2016) (Purser and Bensilum, 2001) (Sime, 1985), which can prolong the evacuation speed and expose people to harm. To reduce evacuation time to protected escape routes, emergency signage must be placed in a manner that makes them noticeable and they must be designed in a way that makes people follow them (Sime, 1985).

Even when emergency signage complies with legislation and standards regarding evacuation of buildings, issues can nevertheless be found and improvements made.
To test the function and visibility of exit signs, the emergency signage of a university building was tested using Serious Gaming (SG), in Immersive Virtual Reality (VR). The VR was viewed using head mounted display (HMD). HMD viewed VR makes it easier to evaluate building design based on 3D models (Petrova et al., 2017). It makes room for increased user involvement (Rasmussen, Gade and Jensen, 2017) (Kuliga et al., 2015) (Svidt and Sørensen, 2012) (Christiansson and Svidt, 2011), and allows simulating dangerous situations without putting the users in harm (Wang et al., 2014). Use of VR additionally supports shared perception and communication leading to better decision making (Niu, Pan and Zhao, 2016) (Roupé, Johansson and Tallgren, 2016).

In VR it is possible to observe human behaviour and track their movements. VR has the potential to act as a simplified mean of communication between users and designers, deepening the understanding of people's needs and wishes with respect to the design (Sørensen and Svidt, 2017). VR use additionally allows changing of the virtual environment (VE) test persons are exposed to, in a more cost- effective way than real life mock- ups (Andrée, Nilsson and Eriksson, 2016; Zou, Li and Cao, 2017) granting a maximum control over the presented scenarios (Kinateder et al., 2014) (Wiederhold and Wiederhold, 2010).

Earlier studies have addressed the use of VR for attaining knowledge of human behaviour during evacuation (Kobes et al., 2010; Gwynne et al., 2016, 2017) the psychological aspects of evacuation (Gamberini et al., 2015), selection of emergency exits (Andrée, Nilsson and Eriksson, 2016), decisionmaking during extreme situations, (Rüppel and Schatz, 2011) and the difference between VR evacuation training compared to traditional training approaches, such as: video, posters, seminars, courses and evacuation drills (Feng et al., 2018).

VR has additionally been concluded as an efficient tool for providing understanding of the evacuation process to building designers and end users (Rüppel and Schatz, 2011; Zhang and Wang, 2012) and make people accustomed to a building environment and 
prepare them for an evacuation (Wang et al., 2014).

Use of VR in evaluation of exit sign placement and escape route design, is nevertheless a novel approach in the building industry (Kobes et al., 2010; Kinateder et al., 2014; Andrée, Nilsson and Eriksson, 2016).

In the past twenty years, Serious Gaming (SG) has become an increasingly used tool for training and behavioural analysis (Feng et al., 2018) (Connolly et al., 2012) (Kobes et al., 2010). A transverse characterization of SG has however still not emerged in the industry (Connolly et al., 2012) (Susi, Johannesson and Backlund, 2007). In this paper we use the definition of SG as formulated by (Susi, Johannesson and Backlund, 2007), also used by (Feng et al., 2018) : "The application of gaming technology, process, and design to the solution of problems faced by businesses and other organizations. SGs promote the transfer and cross-fertilization of game development knowledge and techniques in traditionally non-game markets such as training, product design, sales, marketing, etc."

Nudging refers to purposefully changing the architectural elements that influence people's behaviour. This is done by making changes to the environment guiding and enabling individuals to make desired choices almost automatically (Lehner, Mont and Heiskanen, 2016). In this study, we used nudging principles to find improved solutions to the emergency signage design.

This paper focuses on design and improvement of emergency signage, answering the research question: How can emergency signage design and placement be improved using VR based on a Serious Game scenario?

\section{Methodology}

The research design of the study is in the following described through 5 subsections as shown in Figure 1.

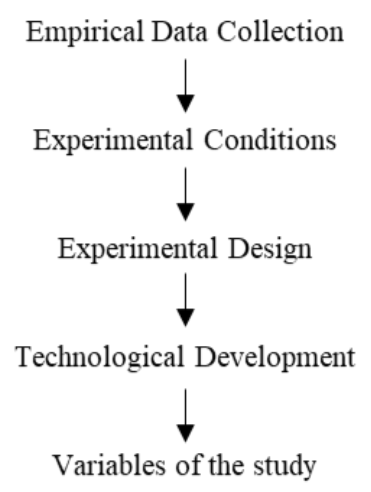

Figure 1 The 5 subsections of the research design.

\section{Empirical data collection}

The research question was answered through a design driven co- creation methodology, involving both expert interview persons and building user testing through VR.

Interviews were conducted using the Contextual Design Inquiry methodology (Beyer and Holtzblatt, 1997) Both experts and building users were interviewed immediately after having been immersed into VR. Written questionnaires were also used in collecting empirical data.

Selection of expert interview persons was based on a stakeholder analysis, revealing which stakeholders held the highest interest and influence over the test building's escape route design. In this paper a District Surveyor can be both building technical surveyors and fire safety officers (principal surveyor). Two persons with many years of experience in fire safety issues and hazards were therefore chosen as interviewees, acting as District Surveyors during the experiment.

Test persons were selected, considering the potential users of the building such as students, teachers, researchers and visiting professors. It was stressed involving people both with and without knowledge of the escape route design of the building as recommended by (Trafik- og Byggestyrelsen, 2016).

\section{Experimental conditions}

The experiment involving the building users, was conducted during an exploration event in Northern Jutland, Denmark, called The Digital Days 2018, where experiment participants living up to the experimental conditions were found.

The experiment was divided into three test phases.

A) Expert involvement: Experts explored the existing exit signage guiding towards the protected escape routes in the architectural and engineering building model as well as the VR, using both HMD and monitor display.

B) Improvement of the VR: Experts proposed four changes to the escape route design, in order to improve the exit signage and the guiding to protected escape routes as shown in Table 1.

C) User involvement: A user group of 20 people explored the original escape route design of the test building through VR, by reacting to the SG scenario. Another group of 20 people then tested the escape route design after improvements were made, based on expert proposals.

Improvement of the escape route design was additionally based on nudging principles. Nudging works though four types of tools: 1) simplification and framing of information, 2) changes to the physical environment, 3) changes to the default policy, and 4) the use of social norms (Lehner, Mont and Heiskanen, 2016). 
Table 1 The four improvements made to the VR

\begin{tabular}{|c|l|}
\hline 1. & Pictograms on escape route doors \\
\hline 2. & Lowering of exit signs \\
\hline 3. & Light arrows showing direction to doors \\
\hline 4. & Permanent indication of perimeters \\
\hline
\end{tabular}

Simplification was used in the SG by making the scenario more straight forward. Improvements of the escape route signage in the VE was made by changing the placement, the lighting and colouring of the emergency signage.

\section{Experimental Design}

The experiment was designed as a SG, allowing test persons to do a playthrough of a scenario by entering and navigating around the test building in VR with the purpose of assembling in a meeting room. Upon arriving in the building, the text: "Please assemble on the $3^{\text {rd }}$ floor of the building, in room 1.308 for a meeting" was displayed. Upon arriving in the meeting room, the building's warning system announced: "Please follow the emergency signage of the building towards the protected escape route in order to exit the building. Please do not use the elevator".

A provocative scenario of a fire, as shown in Figure 2 was inserted into the same route the test persons followed to the meeting room, intending to force test persons to use the nearest emergency exit. The provocation was furthermore inserted to force a mental and behavioural response of the test persons similar to

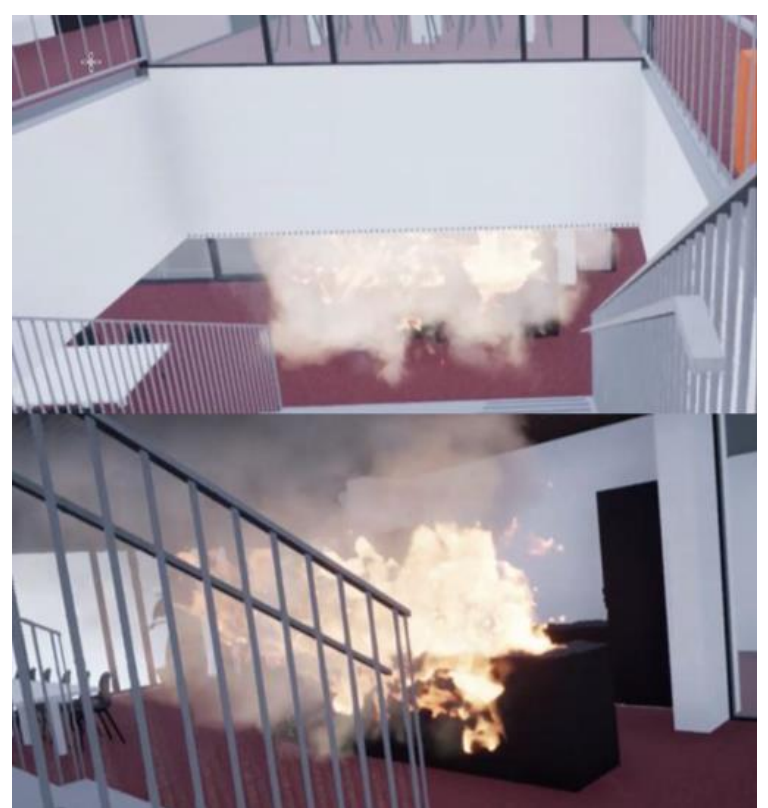

Figure 2 Visual fire presented to the test persons in the VR Serious Game scenario. real stressful situations, as described by (Cao, Lin and Li, 2019) (Zou, Li and Cao, 2017).

After completing the SG in VR, each test person gave feedback on the questions shown in table 2 .

Table 2 Feedback questions

\begin{tabular}{|l|}
\hline Questions \\
\hline $\begin{array}{l}\text { How hard was it to identify the escape } \\
\text { routes of the building? }\end{array}$ \\
\hline $\begin{array}{l}\text { Did the scenario make you aware of } \\
\text { missing exit signage? }\end{array}$ \\
\hline
\end{tabular}

The VR model was then updated based on expert evaluation and change proposals, before being presented to the user group. The users were then asked to evaluate different improvement solutions based on the expert proposals (Table 1). Nudging principles were also used in selection of improved solutions.

One of the design changes was inserting pictograms on emergency exits, as shown in Figure 3.

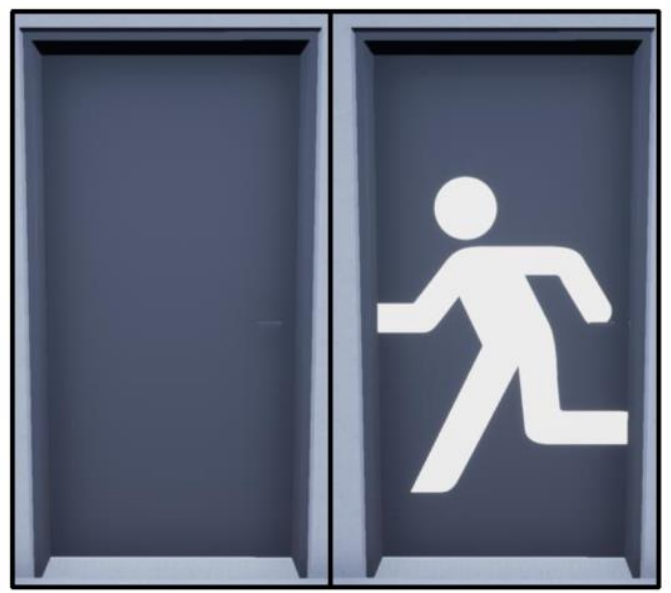

Figure 3 Left door: Before update of the VR. Right door: After the update of the VR.

\section{Technological development}

The building used for placement and design testing of the emergency signage, was the Department of Civil Engineering at Aalborg University, Denmark. Initial analysis of the actual building revealed some unsuitable design choices and placements of the existing emergency signage, making the building relevant for user involved VR evaluation.

The building's emergency signage and protected escape routes were designed based on Danish Building Regulations 2015 and the Danish Sample Collection of Fire Protection of Construction (Trafik- og Byggestyrelsen, 2016). 


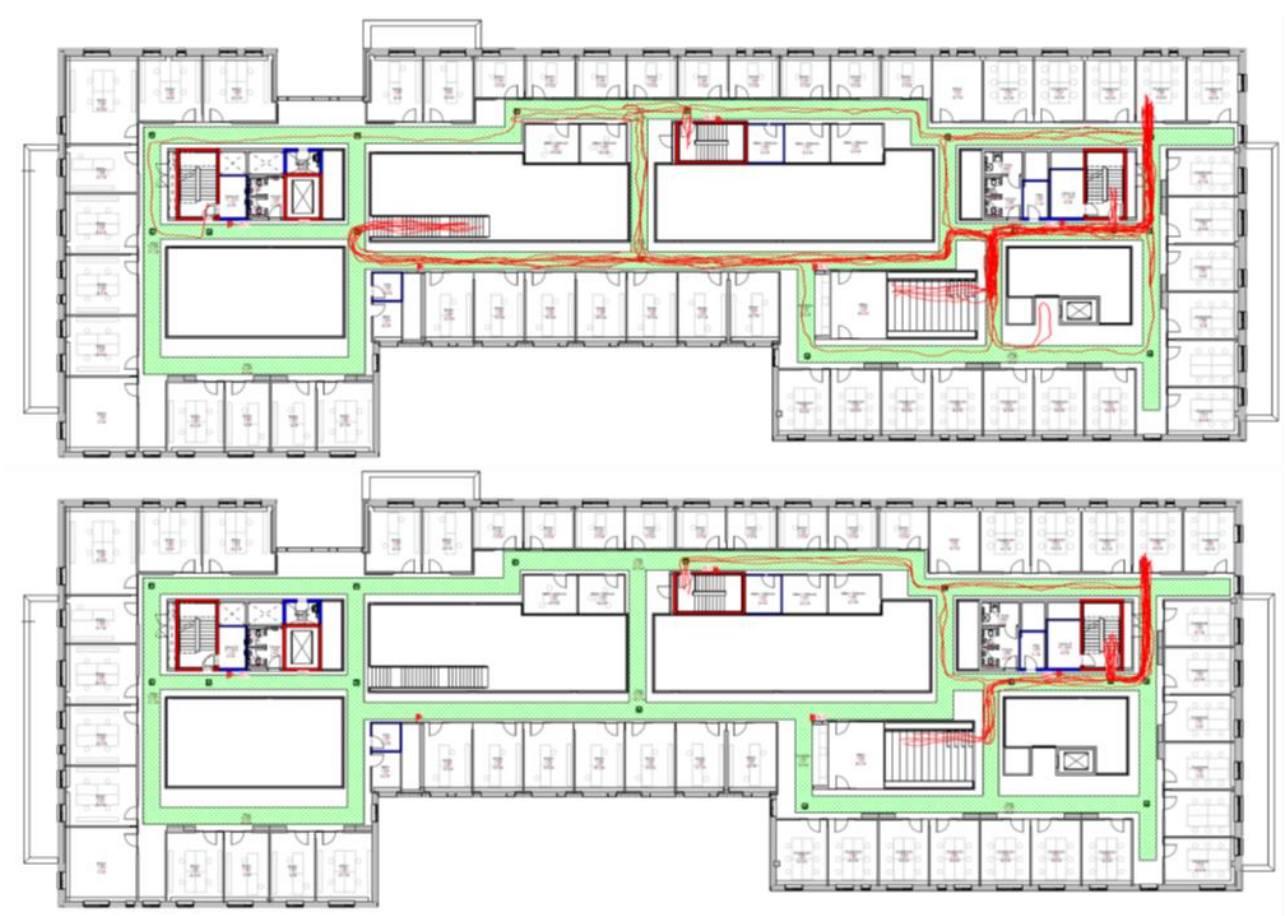

Figure 4 The upper floorplan shows the test person's evacuation route, on the $3^{\text {rd }}$ floor before changes were made to the VR. The lower floorplan illustrates the evacuation route test persons took on the $3^{\text {rd }}$ floor after changes were made to the VR.

Emergency signage in the SG VR was modelled based on the existing 3D models of the building and the documentation used by the owner to attain the building permit.

The VR was built using a 3D model of the test building in the .IFC format and the Unreal 4 game engine.

Only rooms relevant to the test scenario were furnished, and technical equipment e.g. elevators were not functioning in VR, as elevators are not approved for use during fire evacuation in the real building.

The Oculus Rift CV1 head mounted display (HMD) was used in all test sessions. The HMD was connected to the PC via cable. Oculus Touch controllers were used to manoeuvre in VR.

\section{Variables of the study}

The test persons were in the age between: 20 and 29 . 95 per cent were male, 75 per cent students, 10 per cent employed in engineering companies whilst the remaining 15 per cent were working in construction, architecture or education.

\section{Results and discussion}

Multiple conclusions were derived from the data collected after the test person's completion of the SG and the follow-up interviews.

As shown in Figure 4, the test persons (illustrated as red lines) were struggling finding the closest emergency exit to a protected escape route from the starting point in room 1.308 in the test building. Some test persons were even running to the far end of the building before finding a protected escape route. 80 per cent of the test persons failed to use the nearest emergency exit. After the VR was improved, 13 of 20 persons used the nearest emergency exit, equivalent to 65 per cert.

In the VR based on the test building's existing emergency signage only 40 per cent of test persons used protected escape routes to evacuate the building. In the improved version 80 per cent did.

Even though the fire scenario playthrough on the $2^{\text {nd }}$ floor was supposed to hinder test persons from evacuating through the same route they had entered the building, 25 per cent of the test persons ignored the flames in the SG before changes were made to the VR. In the improved model however, 20 per cent still used the route they entered the building at, despite of the visible flames.

Based on the interviews conducted after completion of the unimproved SG VR, 40 per cent of the test persons rated the escape routes easy to identify, whilst 25 per cent rated them hard or very hard to identify.

Only 10 per cent of the test persons rated the identification of the escape routes to be very easy in the unimproved VR. In the improved VR however, 45 per cent rated the escape routes to be very easy to identify.

With respect to evacuation times, the test persons were timed during their SG playthrough. The evacuation times of the unimproved VR ranged from fastest to 
slowest: $2.36 \mathrm{~min}$ to $1.00 \mathrm{~min}$. In the improved VR it ranged from fastest to slowest: $3.07 \mathrm{~min}$. to $50 \mathrm{sec}$. The spread of the evacuation times was in the unimproved VR: 31 seconds whilst the improved VR had a spread of evacuation times of: 37 seconds.

The data showed that the evacuation time went from an average of $1.32 \mathrm{~min}$. in the unimproved VR to 1.15 min. in the improved VR, thus a 19 per cent improvement, making it possible to conclude the use of VR for evaluation of emergency signage an efficient tool for improving evacuation times.

\section{Improvement rating}

As earlier described (Table 1) four different improvements were made to the VR to heighten the salience and intuitiveness of the emergency exit signage. These improvements were rated on a scale from 1 to 5 by the test persons based on four criterion, where 1 was equivalent to the test person strongly disagreeing and 5 equivalent to strongly agreeing. The data was collected using a written questionnaire based on:
1) Visibility
2) Obvious functionality
3) Helpfulness during evacuation
4) Aesthetic impact on architecture

Figure 5 shows the average scores of the solutions.

\section{Pictograms on escape route doors}

Pictograms on emergency exits were inserted in the VR. This improvement was rated to be very visible with an average score of 4.65. The test persons furthermore rated the obvious functionality of the change 4.40 and the helpfulness during evacuation 4.20. Regarding the aesthetic impact on the architecture the rating was only 2.05 . This could indicate that the test persons primarily focusses on the practicality of the pictograms. The limited participation of architects in the experiment, could also be a factor in this regard.

As the pictograms are a permanent part of the architecture, it can be argued that the solution will lose its salient function over time, as building users might stop noticing them. This argument also applies to lowering of exit signs.

\section{Lowering of exit signs}

Another improvement of the VR was lowering of the exit signs. In the unimproved model the exit signs were placed just below the ceiling in the test building. After improvements were made, the signs were lowered with approximately $500 \mathrm{~mm}$. creating higher visibility and functionality. The experts noted that people have a tendency to look down during evacuation, clarifying why the average rating of visibility of the lowered signs was only 3.80 . The helpfulness of the lowered signs during evacuation was rated 3.52 and defacing of architecture 2.25, making this improvement less useful and more defacing to the architecture, making it a less feasible solution to aid the evacuation of people.

\section{Light arrows showing direction to doors}

As mentioned earlier, experts noted that people usually look down during evacuation. Light arrows were therefore inserted into VR to direct people toward the emergency exits. This improvement was rated with an average of 4.40 with respect to visibility, which is the same as the pictogram solution mentioned previously. The solution was additionally the highest scoring improvement with respect to helpfulness during evacuation with an average score of 4.35. It furthermore had a score of 2.15 regarding defacing of architecture.

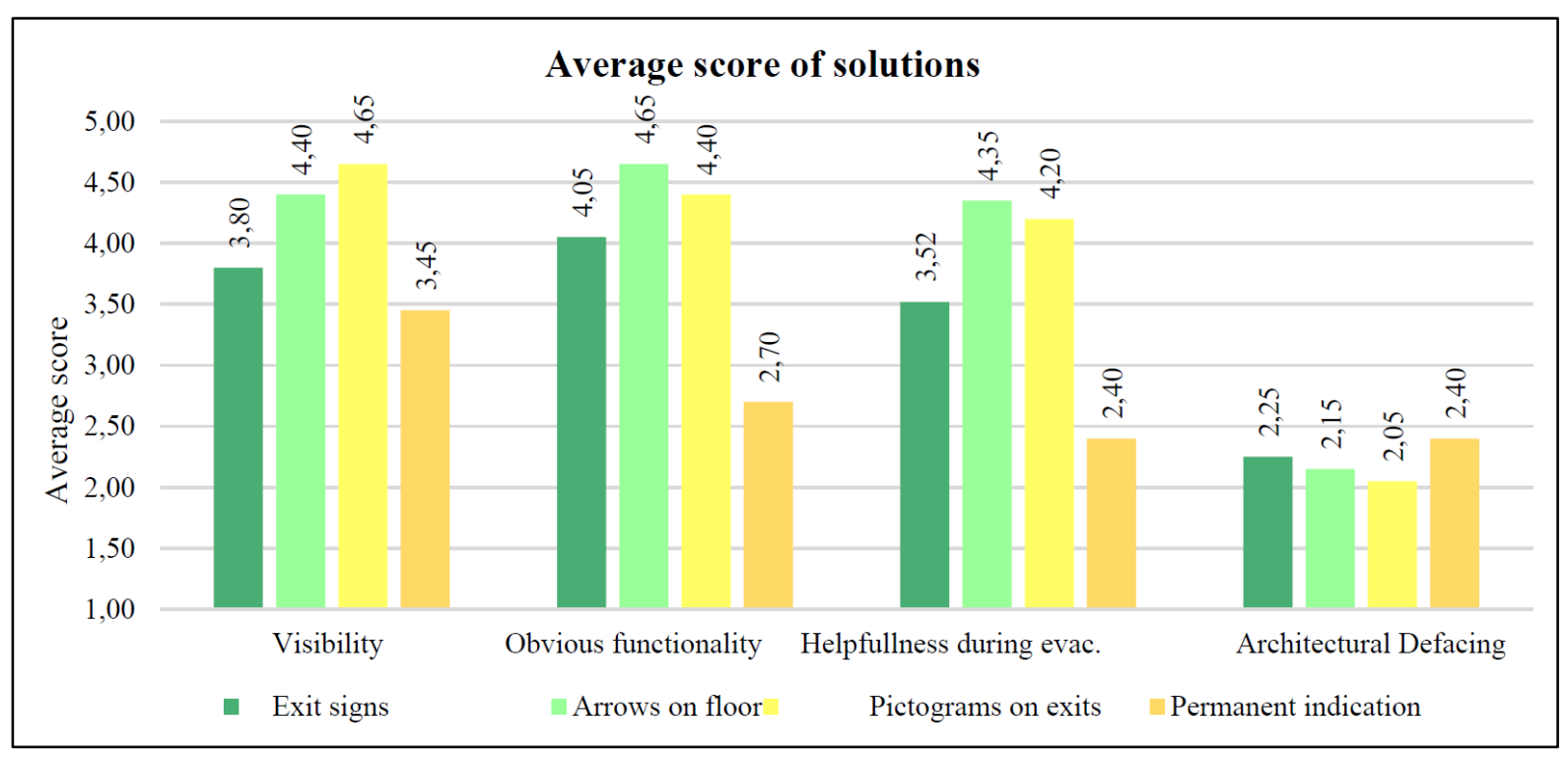

Figure 5 Average scores of the solutions implemented in VR. 
In contrast to the two previously mentioned solutions, the light arrows are not a permanent part of the building's architecture, as they only turn on during evacuation. This means the light arrows will attract attention because they are not noticed on a daily basis by the building users, making this a more salient solution.

\section{Permanent indication of escape routes}

The final solution implemented in VR was a permanent indication of the escape route perimeter on the building's floors. This solution was rated 3.45 in visibility, 2.70 in obvious functionality and 2.40 in helpfulness during evacuation. This means the solution was the least feasible improvement solution in the experiment. With respect to architectural defacing the solution scored 2.40 making the solution the most defacing option.

As the solution would be a permanent visual feature of the building it is likely to become less salient to the building users during evacuation, and might attain more aesthetic value than practical. The permanent indication must furthermore be supported with one of the previously described solutions, as it only indicates the perimeter outline of the escape route with no direct guidance towards protected escape routes.

\section{Nudging the solutions}

The solution options shown in Figure 6, were all analysed based on comments from experts and nudging principles, before being implemented in VR. After the final experiment was conducted, the test persons were asked to rate the solutions.

The response from the test persons indicated that the pictogram and the lowered exit sign solutions would be a better solution than the existing emergency signage. The "arrow on the floor" solution could according to the test persons be improved by supplying

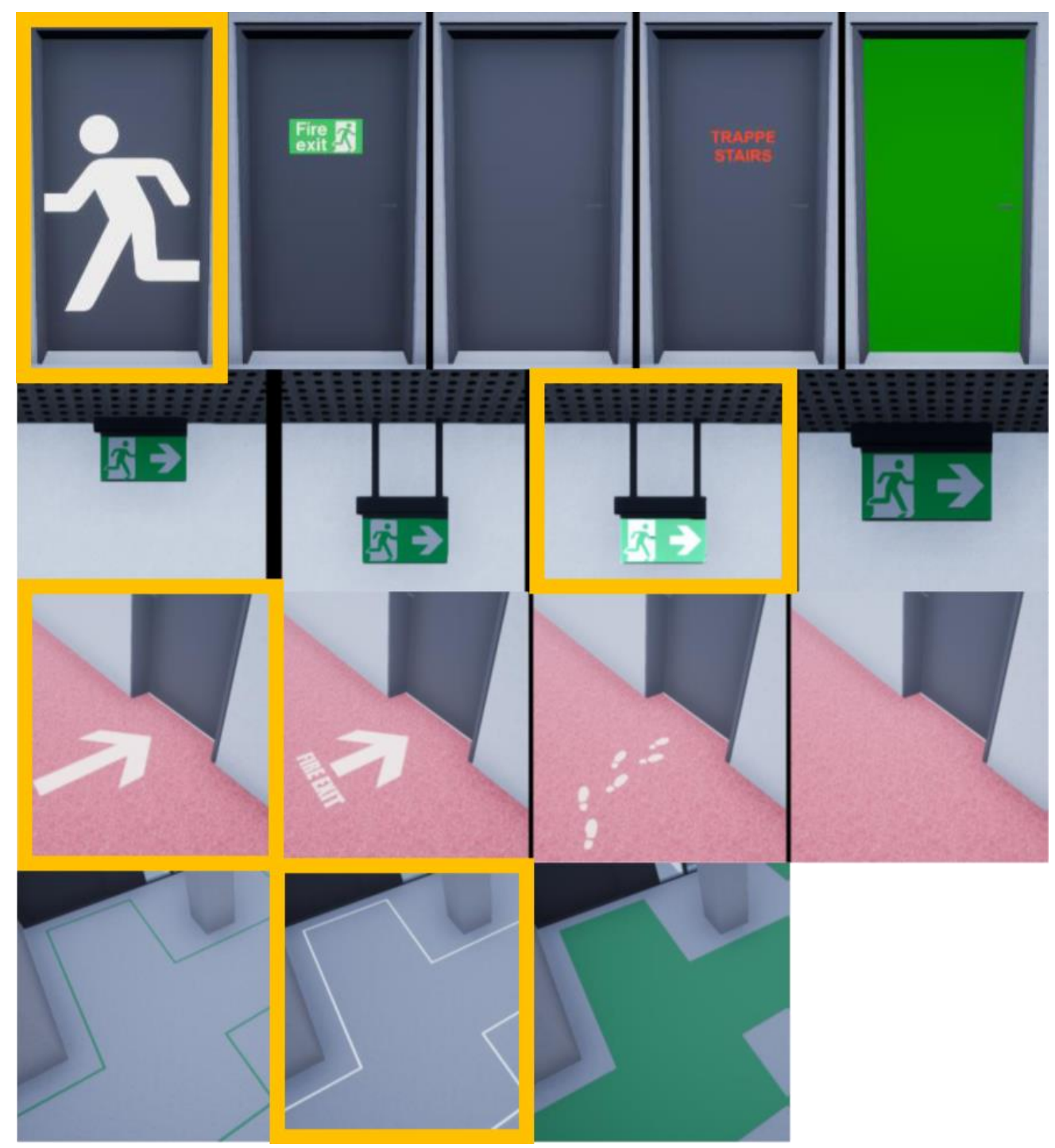

Figure 6 Different solution options. The boxes in yellow frame shows the solutions used in the VR scenario presented to the test persons. 
the arrow with a "FIRE EXIT" caption, to make the meaning of it explicit. 50 per cent of the test persons rated the solution in VR, highlighted in Figure 6, to be good or very good. By supplying the arrow with a caption, its rate however increased to 95 per cent.

With respect to the permanent indication on the floor, 45 per cent rated the green and the white perimeter line to be equally good for guidance towards the protected escape route. However, 65 per cent rated the green coloured full marking the best solution.

The experiment was not conducted again after this evaluation. However, iteration of the experiment could have provided an even better understanding of the function of the emergency signage. In future research additional iterations must therefore be conducted.

\section{Limitations}

One of the primary limitations of the study was the lack of smoke and heat radiation from the simulated fire, allowing people to run through it in VR unaffected.

The human view of $210^{\circ}$ (Traquair, 1938) is in VR limited horizontally to $110^{\circ}$, whilst the vertical view is reduced from $150^{\circ}$ to $110^{\circ}$ (Digital Trends, 2019). This reduction in view might have prevented test persons in discovering signage during the serious game, influencing the documented evacuation times.

As the test experiment of the emergency exit signage in VR only took 5 - 10 min., full building overview was not possible to acquire for the test persons, as it would be the case for people using the building on a daily basis. This might have influenced the evacuation times.

\section{Conclusion}

Emergency signage is an important factor to consider with respect to ease and speed of fire evacuation. Through a Serious Game presented in Immersive Virtual Reality experts and test persons evaluated the design and placement of the emergency signage of a test building. 40 test persons, divided into two groups, completed the Serious Game playthrough whilst their evacuation movement and time was captured. Based on the results from the test of the existing emergency signage, a new Virtual Environment with improved signage was developed and tested with another group of potential building users.

The improvements made based on the initial evaluation resulted in a 19 per cent decrease in evacuation time, and 65 per cent of the test persons using the nearest emergency exit to a protected escape route and out of the test building. This result makes it possible to conclude use of VR for evaluation of emergency signage an efficient tool for improving evacuation times.

\section{Acknowledgements}

The authors would like to thank the participants at The Digital Days 2018, at University College of Northern Denmark, for participation in the experiment. We would further like to acknowledge the corporation of Jens Anker Gere, Jørgen Wiederholt Pedersen and Viet Pham for their assistance. Finally the authors would like to thank the COWI Foundation for financing parts of the work.

\section{References}

Andrée, K., Nilsson, D. and Eriksson, J. (2016) Evacuation experiments in a virtual reality high-rise building: exit choice and waiting time for evacuation elevators, Fire and Materials, 40(4), pp. 554-567. doi: 10.1002/fam.2310.

Beyer, H. and Holtzblatt, K. (1997) Contextual design: defining customer-centered systems. Elsevier Science \& Technology.

Cao, L., Lin, J. and Li, N. (2019) A virtual reality based study of indoor fire evacuation after active or passive spatial exploration, Computers in Human Behavior. 90, pp. 37-45. doi: 10.1016/j.chb. 2018.08.041.

Christiansson, P. and Svidt, K. (2011) User participation in the building process', Journal of Information Technology in Construction, 16, pp. 309334. Available at: http://itcon.org/data/works/att/ 2011_20.content.00616.pdf.

Connolly, T. M., Boyle E. A., MacArthur, E., Hainey, T. and Boyle, J. M. (2012) A systematic literature review of empirical evidence on computer games and serious games, Computers and Education, 59(2), pp. 661-686. doi: 10.1016/j.compedu. 2012.03.004.

Digital Trends (2019) Oculus Rift vs. HTC Vive|Spec Comparison |. Available at: https://www.digitaltrends. com/virtual-reality/oculus-rift-vs-htc-vive/ (Accessed: 3 April 2019).

Feng, Z., González, V. A., Amor, R. and Lovreglio, R. (2018) Immersive virtual reality serious games for evacuation training and research: A systematic literature review, Computers and Education, 27, pp. 252-266. doi: 10.1016/j.compedu.2018.09.002.

Gamberini, L., Chittaro, L., Spagnolli, A. and Carlesso, C. (2015) Psychological response to an emergency in virtual reality: Effects of victim ethnicity and emergency type on helping behavior and navigation, Computers in Human Behavior, 48, pp. 104-113. doi: 10.1016/j.chb.2015.01.040. 
Gwynne, S. M. V., Boyce, K. E., Kuligowski, E. D., Nilsson, D., Robbins, A. P. and Lovrelgio, R. (2016) Pros and Cons of Egress Drills, in Proceeding of Interflam 2016, 14th International Conference on Fire Science and Engineering. $\mathrm{Nr}$ Windsor, -1. Available at: https://www.bertelsmann-stiftung.de/fileadmin /files/BSt/Publikationen/GrauePublikationen/MT_Gl obalization_Report_2018.pdf\%0Ahttp://eprints.1se.ac .uk/43447/1/India_globalisation\%2C society and inequalities\%281sero\%29.pdf\%0Ahttps://www.quora. com/What-is-the.

Gwynne, S. M. V., Kuligowski, E. D., Boyce, K. E., Nilsson, D., Robbins, A. P., Lovreglio, R., Thomas, R. and Roy-Poirier, A. (2017) Enhancing egress drills: Preparation and assessment of evacuee performance, Fire and Materials. doi: 10.1002/fam.2448.

Kinateder, M., Müller, M., Jost, M., Mühlberger, A. and Pauli, P. (2014) Social influence in a virtual tunnel fire - Influence of conflicting information on evacuation behavior, Applied Ergonomics, 45(6), pp. 1649-1659. doi: 10.1016/j.apergo.2014.05.014.

Kobes, M., Helsloot, I., de Vries, B. and Post, J. (2010) Exit choice, (pre-)movement time and (pre)evacuation behaviour in hotel fire evacuation Behavioural analysis and validation of the use of serious gaming in experimental research, Procedia Engineering, 3, pp. 37-51. doi: 10.1016/j.proeng. 2010.07.006.

Kuliga, S. F., Thrash, T., Dalton, R. C. and Hölscher, C. (2015) Virtual reality as an empirical research tool - Exploring user experience in a real building and a corresponding virtual model, Computers, Environment and Urban Systems, 54, pp. 363-375. doi: 10.1016/j.compenvurbsys.2015.09.006.

Lehner, M., Mont, O. and Heiskanen, E. (2016) Nudging - A promising tool for sustainable consumption behaviour?, Journal of Cleaner Production, 134, pp. 166-177. doi: 10.1016/j.jclepro. 2015.11.086.

Niu, S., Pan, W. and Zhao, Y. (2016) A virtual reality integrated design approach to improving occupancy information integrity for closing the building energy performance gap, Sustainable Cities and Society, 27, pp. 275-286. doi: 10.1016/j.scs.2016.03.010.

Petrova, E., Romanska, I., Stamenov, M., Svidt, K. and Lund Jensen, R. (2017) Integrating Virtual Reality and BIM for End-User Involvement in Design: A Case Study, in Lean and Computing in Construction Congress, Proceedings of the Joint Conference on Computing in Construction, Edinburgh: Heriot-Watt University, 1, pp. 699-706. doi: 10.24928/JC3-

\section{7/0266.}

Purser, D. A. and Bensilum, M. (2001) Quantification of behaviour for engineering design standards and escape time calculations, Safety Science, 38(2), pp. 157-182. doi: 10.1016/S0925-7535(00)00066-7.

Rasmussen, M., Gade, A. N. and Jensen, R. L. (2017) Bridging the Gap between Actors and Digital tools in a Knotworking Design Process, Proceeding of When Social Science meets BIM and LEAN, 1, pp. 1-7, Aalborg.

Roupé, M., Johansson, M. and Tallgren, M. V., Jörnebrant, F. and Tomsa, P. A. (2016) Immersive visualization of Building Information Models, Living Systems and Micro-Utopias: Towards Continuous Designing, Proceedings of the 21st International Conference of the Association for Computer-Aided Architectural Design Research in Asia (CAADRIA 2016), Hong Kong, 673-682.

Rüppel, U. and Schatz, K. (2011) Designing a BIMbased serious game for fire safety evacuation simulations, Advanced Engineering Informatics, 25(4), pp. 600-611. doi: 10.1016/j.aei.2011.08.001.

Sime, J. D. (1985) Movement toward the Familiar, Environment and Behavior, 17(6), pp. 697-724. doi: 10.1177/0013916585176003.

Sørensen, J. B. and Svidt, K. (2017) BIM-based Multiuser Collaborative Virtual Environments, Proceedings of eCAADe 35, pp. 111-118, Rome. doi: 978-94-91207-12-9.

Susi, T., Johannesson, M. and Backlund, P. (2007) Serious Games - An Overview. School of Humanities and Informatics University of Skövde.

Svidt, K. and Sørensen, J. B. (2012) Development of a Virtual Reality Solution for End User Involvement in Interior Design, Proceeding of eCAADe 34: Conferences, 2, pp. 541-546.

Trafik- og Byggestyrelsen (2016) Eksempelsamling om brandsikring af byggeri, 2. reviderede udg. 2016. Byggecentrum.

Traquair, H. M. (1938) An Introduction to Clinical Perimetry. Mosby.

Wang, B., Li, H., Rezgui, Y., Bradley, A. and Ong, H. N. (2014) BIM based virtual environment for fire emergency evacuation, Scientific World Journal. Hindawi Publishing Corporation, 2014. doi: $10.1155 / 2014 / 589016$. 
Wiederhold, B. K. and Wiederhold, M. D. (2010) Virtual Reality Treatment of Posttraumatic Stress Disorder Due to Motor Vehicle Accident, Cyberpsychology, Behavior, and Social Networking, 13(1), pp. 21-27. doi: 10.1089/cyber.2009.0394.

Zhang, J. F. and Wang, S. P. (2012) Application of Virtual Reality Technology for Emergency Evacuation in High-Rise Buildings, Applied Mechanics and Materials, 204-208, pp. 4941-4945. doi: $\quad$ 10.4028/www.scientific.net/AMM.204-208.49 41.

Zou, H., Li, N. and Cao, L. (2017) Emotional Response-Based Approach for Assessing the Sense of Presence of Subjects in Virtual Building Evacuation Studies, Journal of Computing in Civil Engineering, 31(5), p. 04017028. doi: http://dx.doi.org/10.5336/ medsci.2009-11027. 